Etnográfica

Revista do Centro em Rede de Investigação em

Antropologia

vol. 15 (3) | 2011

Vol. 15 (3)

\title{
O lugar e o tempo do objeto etnográfico
}

The place and the time of the ethnographic object

\section{Oscar Calavia Sáez}

\section{OpenEdition}

\section{Journals}

\section{Edição electrónica}

URL: https://journals.openedition.org/etnografica/1086

DOI: 10.4000/etnografica.1086

ISSN: 2182-2891

\section{Editora}

Centro em Rede de Investigação em Antropologia

\section{Edição impressa}

Data de publição: 1 outubro 2011

Paginação: 589-602

ISSN: 0873-6561

\section{Refêrencia eletrónica}

Oscar Calavia Sáez, «O lugar e o tempo do objeto etnográfico», Etnográfica [Online], vol. 15 (3) | 2011, posto online no dia 23 outubro 2011, consultado o 10 fevereiro 2022. URL: http://

journals.openedition.org/etnografica/1086 ; DOI: https://doi.org/10.4000/etnografica.1086

\section{(c) (i) (9)}

Etnográfica is licensed under a Creative Commons Attribution-NonCommercial 4.0 International License. 


\section{O lugar e o tempo do objeto etnográfico}

Oscar Calavia Sáez

A MINHA CONFERÊNCIA SE OCUPA DE DOIS TEMAS BEM DIFERENTES. De um lado, o da epistemologia, um nome pomposo para algo muito cotidiano com que todos aqui, estudantes e professores, devem lidar a toda hora. De outro, o da etnologia amazônica, um terreno mais exótico. Tratarei deles alternadamente ou em uníssono; o que direi sobre a etnologia amazônica enseja dar volume ao pouco que direi sobre a epistemologia, que será aqui minha principal preocupação.

Quanto à etnologia amazônica, vou fazer o que habitualmente se faz ante plateias para as quais esse assunto é mais ou menos arcano - que são a maior parte das plateias. Isto é, um panorama parcial do estado da arte, me referindo a algumas das suas tendências atuais, à luz da minha própria experiência como pesquisador e como orientador de pesquisadores. Quanto à epistemologia, esboçarei um manifesto em prol de um certo fundamentalismo etnográfico.

Devo confessar que o título original desta conferência era mais bombástico ou quiçá mais derrotista, podem escolher: "Da etnografia como fracasso metódico". Foi, em tempo, substituído por outro, entendo que com bom critério: talvez sejam necessários muitos anos para apreciar os atrativos de um fracasso metódico, e sabiamente a universidade evita anunciar um lema que não serviria de incentivo aos seus alunos.

É a primeira vez na minha vida que dou uma conferência com nome. Neste caso, a Aula Ernesto Veiga de Oliveira. ${ }^{1}$ Nestes casos, é costume começar com 
um elogio ou uma referência ao patrono da conferência, que acaba sendo quase sempre retórica vazia, seja porque o conferencista tem ideias ou conviç̧ões muito diferentes das daquele (o epônimo da conferência costuma ser um vulto muito antigo) ou porque simplesmente não o conhece. $\mathrm{O}$ mais honesto seria, quiçá, evitar esse protocolo, mas, na dúvida, eu decidi ao menos folhear um livro de Ernesto Veiga de Oliveira sobre costumes e festas dos camponeses de Portugal. O tema não estava tão longe assim do que foram as minhas primeiras pesquisas como egresso da graduação na Espanha, mas certamente os argumentos de Ernesto Veiga de Oliveira têm pouco a ver com o que eu mesmo cheguei a dizer a respeito dos costumes e das festas dos camponeses espanhóis.

Havia porém um detalhe relacionado com a ideia central de minha palestra, e que me apareceu no prólogo em que Ernesto Veiga de Oliveira fazia uma cálida lembrança do seu tempo de pesquisador de campo: o que teria sido um fracasso para Ernesto Veiga de Oliveira? Imagino que o pior fracasso para ele seria chegar demasiado tarde. Isto é, chegar quando a modernização da vida dos lavradores acabasse com essas festas e essas tradições que almejava coletar, ou quando a morte tivesse já levado os seus melhores conhecedores. O conservadorismo salazarista atava curto o primeiro perigo, mas nem Salazar podia impedir o segundo. De fato, desde o seu início como disciplina formal, a antropologia contou com a certeza de que estava a estudar um objeto em vias de desaparição; nasceu já com pressas. Essa é uma situação bem peculiar. Psicólogos ou historiadores não têm pressa. Os arqueólogos, por exemplo, fazem às vezes arqueologia de urgência quando aparecem restos de um foro romano no solo onde vai ser construído um centro comercial. Mas, em geral, assumem que o passado é permanente e fica bem guardado alguns centímetros abaixo do chão. Há mesmo a prática de preservar fragmentos no meio das escavações, sem abrir, para que eles esperem lá futuras revisões do passado. A etnografia, pelo contrário, nasceu fadada a ser sempre uma pesquisa de urgência, onde o presente etnográfico está constantemente, não a se tornar passado, mas a desaparecer, porque não se tornará passado pleno se alguém não o registrar agora.

É claro que, ainda chegando em bom tempo, com os mais velhos do lugar em boa saúde e com boa memória, o perigo de fracasso ainda existia, e o bom método podia evitá-lo, garantindo uma coleta exaustiva e objetiva. Passando para o título que de fato a minha conferência assumiu, poderíamos dizer que a época de Veiga de Oliveira era a época em que o objeto estava ali, a nos esperar, e não esperaria para sempre. Agora, como sabemos, o objeto não está mais ali, deve ser cozinhado na hora a quatro mãos entre antropólogo e nativo, e de acordo com as normas culinárias do lugar e do momento.

Essa (in)certeza construtivista é, hoje, um dos nossos axiomas centrais: nem todos o proclamamos em altos brados, mas é difícil que alguém se atreva a desafiá-lo. E, no entanto, duvido que ele tenha na prática a fortaleza que mostra na hora das grandes declarações. 
Passemos ao outro tema. A etnologia amazônica é em muitos sentidos um dos ramos mais novos da antropologia mundial. Embora conte com muitos e excelentes precursores, costuma se dizer que só nos anos sessenta ou setenta do passado século ela atingiu os padrões descritivos que agora se entendem indispensáveis. No Brasil é, sem dúvida, o ramo mais prestigioso da disciplina. Num artigo semiautobiográfico e bem-humorado publicado anos atrás, Eduardo Viveiros de Castro sugeria que os etnólogos compõem uma sorte de casta bramânica dentro da antropologia brasileira: não mais detêm o poder político dentro da profissão, mas sim o prestígio supremo que advém de manter o fogo sagrado da disciplina, cultivando seus temas ancestrais e fazendo trabalho de campo lá na aldeia, naquele lugar distante e romantizado. É difícil medir o prestígio, porém basta perceber que, se os etnólogos dificilmente citam os seus colegas de outras áreas, é extremamente comum que estes, por sua vez, citem com maior ou menor competência os etnólogos. Como sabemos, o campo não precisa mais estar numa aldeia remota; mas os antropólogos que pesquisam nas ruas de sua cidade ou nos corredores de sua faculdade tendem a validar sua experiência dizendo que se encontraram neles "como se estivessem numa aldeia remota".

O prestígio dos etnólogos deve-se (entre muitas outras coisas) a que os índios estão aí, como os objetos de antigamente. Nas aldeias remotas. Na sua versão máxima estão aí porque a Amazônia é um dos raríssimos lugares onde ainda há o que ainda é comum chamar povos não contatados, isto é, povos que não mantêm um comércio regular com o resto da humanidade, tão globalizada. Há, segundo informes oficiais, qualquer coisa como duas dúzias de povos isolados ou arredios nas fronteiras amazônicas do Brasil ou dentro de alguma das Terras Indígenas ou Florestas Nacionais demarcadas e preservadas. Esses nomes - isolados, arredios - já indicam que a questão é menos inocente do que pode parecer. Esses povos não são necessariamente, ou sejamos mais claros, nunca são povos que (fortuna sua) não tenham se encontrado com o nosso mundo, mas povos que com razões muito boas o evitam, isto é, arredios. Ou são povos "isolados" num sentido forte, pois nessa falta de comunicação intervém um desígnio do Estado que cria uma espécie de cordão sanitário em volta deles, evitando qualquer tipo de aproximação. O Estado pretende com isso exorcizar os males que, reconhecidamente, se seguem ao contato; mas há nisso, também, algo dessa precaução dos arqueólogos que estimam necessário preservar algum fragmento impoluto do passado.

Boa parte dos povos que protagonizam a melhor etnologia amazônica da atualidade eram arredios cinquenta ou sessenta anos atrás, e sua aparição no cenário nacional foi seguida não muito depois pela realização de trabalhos de campo profissionais. Essa juventude da etnologia amazônica tem algumas consequências juvenis, como o vigor teórico e uma certa tendência à experimentação, mas tem também consequências aparentemente opostas. Isto é, 
dá espaço aos temas clássicos da disciplina (coisas como parentesco, ritual e xamanismo), que em outras áreas rareiam, e também - pois chegou ao campo quando ainda estava fresca a lembrança de uma outra época - a descrições que alguém chamaria de primitivistas.

Evitemos essa caricatura. A revista Veja, que costuma ser porta-voz da grande mineração e do agronegôcio no Brasil, gosta de dizer que os antropólogos acreditam na qualidade primigênia da vida dos índios, e querem preservá-los assim, dentro de uma cápsula de cristal. Isso é mentira. A ideia de que os povos amazônicos são primitivos é, sim, uma noção de sentido comum entre o público brasileiro (e europeu, com certeza) que a revista Veja ou sujeitos afins também agitam quando lhes convém. Um bom exemplo é a introdução do novo código florestal brasileiro, que conclama o desenvolvimento econômico a redimir os povos que padecem atados a umas condições de vida miseráveis e ancestrais. Mas nenhum etnólogo acredita que os povos indígenas sejam testemunhas de modos de vida antiquíssimos, nem quer mantê-los em nenhuma cápsula. Isso acontecia de fato há algum tempo: lembremos de Robert Jaulin, que devia fazer seu trabalho de campo nu para não induzir os índios a usarem calças; mas Jaulin foi quase contemporâneo de Veiga de Oliveira... Uma primeira visita a campo será bastante para provar a qualquer um que as sociedades indígenas vivem neste século, são dinâmicas e muito capazes de mudar por si mesmas, e que mesmo se não o fossem sobrariam os agentes externos a obrigá-las a tomar alguma providência neste sentido. A maior parte dos etnólogos, de resto, está implicada em projetos de desenvolvimento sustentável ou afirmação cultural que jamais vão ter como resultado uma preservação do passado (que de resto seria, em si mesma, outro tipo de mudança). De fato, num país onde os historiadores em sua maior parte compartilhavam anos atrás essa ilusão do índio como passado remoto, foram em boa medida os etnólogos os que saíram a reivindicar a historicidade das sociedades indígenas.

Mas na etnologia brasileira há sim, apesar disso tudo, uma espécie de objeto permanente. Não me parece adequado chamá-lo de primitivista, porque tudo o que acabei de explicar acima o esvazia de sua substância primitivista, e talvez não seja assim tão necessário procurar um nome para ele. Basta descrever como ele se manifesta.

Talvez seja interessante procurá-lo precisamente nessa vertente de estudos que mais tem feito por descartar o sofisma do primitivismo: a história indígena, em que eu mesmo me iniciei como etnólogo mais de vinte anos atrás sob a direção de Manuela Carneiro da Cunha. Numa primeira fase, os estudos de história indígena se concentravam na exumação do passado, tentando desmentir dois tópicos: o da inexistência de documentação e o da falta de memória das próprias sociedades indígenas. Num segundo passo, isso levava também a rever alguns conceitos a respeito da história tal como ela foi pensada a partir da experiência europeia: há historicidades outras para além daquela que tem 
sua origem em Heródoto e Tucídides. Recentemente, porém, o interesse pela história indígena tem se dirigido ao que está a acontecer agora perante os nossos olhos: coisas como a introdução, já não marginal mas massiva, do dinheiro em algumas economias indígenas, a urbanização, o uso das novas tecnologias pelos índios, etc.

Todos esses assuntos são afins aos dos velhos estudos sobre aculturação, que descreviam culturas locais assimiladas por outra cultura mais poderosa, ou pelo que depois se chamou de sistema mundial, ou ainda mais tarde globalização. Mas essa coincidência apenas serve para sublinhar a divergência: em lugar de retratar um englobamento inevitável do local, a história indígena sublinha o vigor do local. O dinheiro que entra em grandes somas na aldeia Mebengokre não está a introduzir de golpe os Kayapó na economia financeira e capitalista, porque ele vem a servir um sistema hierárquico que é perfeitamente local, e que antes da chegada do dinheiro se alimentava de outro tipo de bens. A descrição que César Gordon fez desse processo é sumamente rica, e equivale à que já fez Marshall Sahlins do setor transpacífico do sistema mundial, mostrando como a ecumene capitalista, aparentemente racional e global, se compõe de processos locais irredutíveis a motivos universalistas. Em lugar de narrar a expansão fatal do Sistema, mostra-se como os povos autóctones adotam ou adaptam para benefício da sua estrutura as eventualidades da história. $\mathrm{Ou}$, aproveitando uma metáfora que o modernismo brasileiro de Oswald de Andrade chancelou, como eles canibalizam o capitalismo, ou o cristianismo, ou a tecnologia. O paradoxal aqui está em que, querendo fazer dos índios sujeitos e não apenas matéria passiva da história, pareceria que se acaba por afirmar algo assim como uma estrutura permanente, esse princípio particular que consegue se impor às novidades.

É claro que pode se fazer uma outra leitura: não há tal estrutura permanente, o que permanece é precisamente a capacidade de alteração. Frente a sociedades que usam todo tipo de recursos - escrita, monumentos, constituições - para dar substância às estruturas e medir em referência a elas o volume da mudança, haverá uma parcela da humanidade infensa a essa preocupação e a essa tendência, que viva a história historicamente, tomando a mudança como dado irredutível. As sociedades indígenas estariam nessa parcela, ou, hoje em dia, a constituiriam quase que em exclusivo.

Nesse pólo encontramos uma outra vertente da etnologia brasileira atual, com certeza a mais conhecida fora do Brasil: a dos trabalhos de Eduardo Viveiros de Castro dedicados ao perspectivismo ou ao canibalismo ameríndios. A mudança do conceito titular não deve ocultar que trata-se sempre de um mesmo movimento, em direção a uma etnoepistemologia em que o sujeito é dado e o objeto é construído, e em que o ser é apenas o caso limite do devir.

Os trabalhos de Viveiros de Castro se apoiam numa bagagem filosófica considerável. Não falta, de fato, quem sugira a sua redução à obra de certos 
filósofos europeus, travestidos de índios para a ocasião. Discordo dessa crítica fácil: na etnologia, onde se descreve uma ordem indispensável e eficiente, o devir alcança uma densidade que não se encontra quando ele é apenas uma alternativa nômade à razão estável da sociedade. É verdade, porém, que essa obra fica de praxe orientada à filosofia: o seu campo de debate habitual é muito próximo daquele do velho, e de vez em quando renovado, debate sobre a racionalidade.

Em rigor, poderia ser de outro modo. Uma epistemologia onde o sujeito é dado e o objeto é construído poderia ou deveria suscitar outras descrições do espaço, do parentesco, do tempo. Na verdade, o perspectivismo chega a ser uma proposta metodológica nova que está por ser posta em prática. Isso pode ser uma impressão pessoal e limitada: a produção etnológica brasileira (ou a produção etnológica mundial que se congrega no Brasil) é muito vasta, e quem trabalha como professor tende a se focar naquela produção em que exerce um papel mais ativo: muito do que está a ser feito me escapa. Mas com essa restrição, repito, creio que essa etnologia perspectivista está por ser feita. E não é uma necessidade histórica que seja feita alguma vez: exigiria recursos descritivos bastante diferentes daqueles a que estamos acostumados, e que quiçá exigiriam grande inventiva para se tornar compreensíveis.

O resultado é que a etnografia, malgrado as suas conviç̧ões, continua ancorada nas permanências. E que, malgrado a referência quase obsessiva ao perspectivismo ameríndio na etnologia brasileira e amazônica, ele costuma fazer o papel não de etnoepistemologia, mas de objeto. Um objeto conceitual que dá fé de uma diferença, que aponta para uma permanência indígena diferenciada, ou uma diferença indígena permanente. Manter uma língua ou um complexo ritual próprios, como manter uma prática regida por um sistema de parentesco peculiar, eram já marcas distintivas. A essas marcas soma-se agora uma epistemologia própria. Com frequência, o perspectivismo ameríndio aparece nas etnografias não como uma alternativa descritiva, mas como um elemento a mais da identidade indígena.

Matizemos. Afinal, que a etnologia fale de uma diferença permanente é algo que não se deve apenas ao juízo dos etnólogos; responde a uma demanda dos nativos, ou pelo menos de um setor peculiarmente ativo do movimento indígena: os índios precisam de uma diferença permanente para se livrar do destino ao qual os fadava uma identidade provisória. Trinta ou quarenta anos atrás a identidade indígena no Brasil era um complicado artefato no qual não podiam faltar peças: se os índios deixassem de pintar o corpo, ou modificassem seu estilo de moradia ou seus hábitos econômicos, não digamos se adotassem uma religião estrangeira, estavam deixando de ser índios, e portanto deixando de fazer jus aos seus direitos de primeiros ocupantes para trocá-los pelos direitos reservados à imensa maioria do povo brasileiro, isto é, quase nenhum. Aliás, era isso o que se esperava que acontecesse antes ou depois com todos 
eles, que se integrassem na base da pirâmide. É isso que estou chamando de identidade provisória. A diferença permanente é o exato inverso disso: ela não precisa encarnar em rituais, estilos de vida ou pinturas corporais, ela é uma interpretatio que sempre permite ver constantes autóctones sob qualquer última moda. As duas vertentes da etnologia brasileira atual que acabei de comentar fornecem formas brilhantes de atender a essa demanda, e seu sucesso faz que sejam constantemente repetidas.

A etnologia brasileira dos últimos decênios tem mostrado que os índios e tudo o mais que lhes advém (a globalidade, a história mundial) não estão numa relação de passado ou presente, como pretendiam evolucionistas ou teóricos do etnocídio. Que também não estão numa relação de conteúdo e forma externa, como pretendiam os teóricos da resistência cultural. Não: os índios mudam, e mudam genuinamente. É isso, de fato, o que eles sabem fazer melhor que ninguém, o que os caracteriza, o que os diferencia. A estrutura e a história não são partes de uma dicotomia, são mais como o fundo e a forma intercambiáveis de um desses desenhos de Escher que podem ser vistos como pássaros pretos sobre um céu branco e como pássaros brancos sobre um céu preto. Mas há um hábito, ao qual os etnólogos se resignam com facilidade, que faz que só uma dessas leituras seja levada a sério. Por assim dizer, há pássaros $\mathrm{A}$ e pássaros $\mathrm{B}$, mas apenas os pássaros $\mathrm{A}$ voam, caçam ou mergulham realmente. Dos pássaros $\mathrm{B}$, aparentemente, não há muito que dizer, salvo que nos seus interstícios permanecem visíveis os pássaros A. Demonstrou-se que os índios continuam aí, o que é, em si, muito interessante; há também muito interesse em mostrar o que eles estão a fazer de novo - mas muito pouco pelo novo que eles estão a fazer. A etnologia não tira as consequências do que já sabe; tem um potencial histórico e perspectivista que continua a usar com parcimônia.

Creio que está na hora de modificar uma afirmação que fiz páginas atrás: já se disse suficientemente que a etnologia amazônica é nova, e é óbvio que essa juventude se obtém a troco de empurrar parte da sua história a esse limbo ilustre dos precursores. Mas é que costumamos fazer a mesma coisa com a antropologia em geral; não tem sido incomum, de Malinowski até os dias de hoje, ouvir dizer que a antropologia é uma ciência nova. É tão nova assim? Já produziu uma massa considerável de estudos, já deu lugar a sínteses teóricas ambiciosas, está institucionalizada em todo o planeta. Na verdade, reconheçamos, a antropologia sonega a sua idade. Encontra-se em plena maturidade; e, se quisermos ser pessimistas, mostra alguns signos de envelhecimento, similares aos do envelhecimento de qualquer um de nós. Ou seja, não é que tenha esgotado suas virtualidades, nem que falte energia para realizá-las, mas simplesmente que alguns padrões, alguns ritos ou rotinas tomaram um espaço muito amplo, e vivem por si mesmos se repetindo indefinidamente.

Viro a página, e volto ao outro tema da minha conferência, aquele sobre o qual vou dizer coisas pouco originais. Até porque a conclusão é bem conhecida: 
acabarei fazendo essa espécie de elogio da etnografia muito comum na antropologia brasileira.

Tenho uma já longa experiência como orientador de pesquisas de doutorado, mestrado e graduação. Uma das minhas obrigações é ajudar os alunos a fazer um projeto, e a que dentro desse projeto definam um objeto de pesquisa. Nem sempre é fácil convencer os alunos de que os objetos não estão aí fora, ou de que não mais estão aí fora, como no tempo de Veiga de Oliveira. Habitualmente essa tarefa passa por algumas noções rudimentares de filosofia da ciência, epistemologia e assim por diante, incluindo um destilado de noções popperianas que nos indica que o objeto da ciência encontra-se na interseção entre o reino do saber estabelecido e esse território do não conhecido, por definição informe e infinito. Isso significa - sabem-no bem todos os professores, e não deixam de repeti-lo aos alunos - que nenhuma pesquisa pode ser feita sem conhecimento da literatura geral e especializada. Nada pode se trazer do campo se, como pretendiam alguns empiristas ingênuos, vai-se a ele de mãos vazias. O que é, de resto, impossível: como humanos, temos noções sobre tudo quanto é humano, e as temos desde antes de saber formulá-las. Conhecê-las e reconhecê-las detalhada e explicitamente não é apenas a melhor opção, é quase a única.

Os alunos aprenderam bem disso, e estudam muito para elaborar o seu projeto. Com grande esforço, elaboram um objeto de pesquisa no qual, tomando como exemplo o caso da etnologia, têm um papel quase indispensável teorias como as que citamos acima: o perspectivismo ameríndio, a domesticação indígena das invenções do homem branco; há muitos outros, mas esses raramente faltam.

Os projetos, melhores ou piores, abrem o caminho para o trabalho de campo, e a partir desse momento os jovens pesquisadores se dividem em dois grandes grupos como se caíssem sobre um telhado de duas águas: fadados ao sucesso e fadados ao fracasso. Não me refiro à previsível diferença de habilidades ou sorte, mas a uma outra diferença que não é nova mas que no atual sistema de produção da ciência costuma ter uma consagração imediata. Os fadados ao sucesso são aqueles cujo projeto mostra uma extrema eficiência: os pesquisadores vão a campo e se dirigem em linha reta (tão reta quanto for possível) ao seu objeto. O captam, o descrevem, o enriquecem ou alteram na medida necessária. Em boa parte, esse sucesso se deve a uma precaução: a de escolher bem o lugar onde a pesquisa será realizada, ou seja, um campo adequado ao projeto, às vezes já devidamente explorado por um sênior em outros tempos, e com nativos qualificados e experientes. Eventualmente isso pode exigir que se descartem campos inadequados, até achar aquele que preencha os requisitos do projeto. Em geral, esse modo de proceder conduz à felicidade geral: o pesquisador acaba sua pesquisa em tempo hábil (muito importante!), obtém boa nota, seu orientador o parabeniza e se parabeniza pelo sucesso, e o trabalho passa a ocupar um lugar mais ou menos relevante na bibliografia a respeito. 
Há uma grande quantidade de trabalhos desse tipo, que gozam de um reconhecimento geral, e eu pessoalmente acho alguns deles soberbos. Nem todos, porque esse sucesso reserva também um lugar importantíssimo para a replicação da doutrina.

Pelo outro lado, há os que desde muito cedo parecem fadados ao fracasso. A escolha de campo se revela imprudente, ou se torna inadequada por motivos diversos, e o projeto passa a ser não um roteiro, mas uma espécie de carga da qual o pesquisador terá sorte se conseguir se desvencilhar a tempo. O objeto da pesquisa revela-se um objeto sem objeto, e os infelizes pesquisadores se lamentam de que não encontram no campo nada daquilo que lá os fez ir. Com frequência, isso vem acompanhado de peripécias alarmantes: mudança de tema, mudança de orientador, mudança de curso. Às vezes, o desassossego ultrapassa o terreno acadêmico e acaba em divórcios, doenças ou tratamento psiquiátrico. Não é necessário dizer que o resultado disso tudo é o exato oposto do anterior: trabalhos que jamais chegam a concluir, arranjos mais ou menos toleráveis para salvar a pesquisa. Ou, também, trabalhos que alcançam algum tipo de redenção final. Se pelo menos chegam a termo, alinham-se nas bibliotecas universitárias nas mesmas prateleiras em que se encontram os sucessos. Entre eles, como poderia se esperar, abundam os absolutamente descartáveis, ou só parcialmente interessantes. Mas há também trabalhos excelentes, embora dificilmente cheguem a obter o grau de reconhecimento que obtêm os da primeira categoria. Pessoalmente, considero que é nesses últimos trabalhos onde podemos encontrar a verdadeira razão de ser da antropologia.

Isso pode parecer uma declaração irresponsável; o é, quase sem dúvida, para as instituições educativas e científicas do Estado, que vêm dando à antropologia um crédito cada vez maior. Como pode sequer se sugerir algo desse tipo, quando há tanto investimento público num sistema de produção do conhecimento que requer previsão, planejamento, prazos? E quando a demanda de conhecimento antropológico cresce exponencialmente? Nunca antes na história desta disciplina, desde que felizmente foram descartadas as teorias higienistas e racistas de uma certa antropologia cem anos atrás, tinha estado a antropologia em condições de disputar a hegemonia das ciências humanas à história, à psicologia ou à sociologia. Agora está: os cursos de pós-graduação em antropologia se multiplicam e atraem uma grande quantidade de alunos; o sucesso é tanto que começaram a proliferar também os cursos de graduação em antropologia. Eu, particularmente, olho esse sucesso com muita desconfiança. Não me parece mal, em si, que tenhamos muitos alunos e nos outorguem bolsas, financiamento de projetos, etc. Mas como harmonizar isso com o que me parece ser a razão de ser da antropologia, isto é, aquilo que acabou por fazer de mim um antropólogo e não alguma outra coisa?

Temos repetido até a saciedade, mas com um júbilo nunca esmorecido, que a antropologia é uma disciplina indisciplinada, e não uma ciência normal, no 
sentido que Kuhn dava ao termo. E, no entanto, essa ciência indisciplinada funciona normalmente. Produz teses sobre os mais variados assuntos num ritmo previsível, assume regularmente o papel de savant junto às instituições, e de cara ao grande público tem resposta para praticamente tudo. É essa a ciência indisciplinada, fragmentar, nômade, gerada por um embate quase imprevisível com o Outro?

Há três tipos de coisas que as ciências fazem, e que a antropologia se considerou capaz de fazer ou vir a fazer em algum momento. Uma, elaborar teoremas, enunciar princípios, formular grandes teorias. Outra, traduzir, interpretar. Outra, enfim, descobrir novos objetos. Em maior ou menor medida, todas as ciências pretendem fazer essas três coisas.

No caso da antropologia, não parece que o seu destino esteja na elaboração de Grandes Teorias Unificadas. O problema não é que estas faltem, mas que sobrem; o índice de mortalidade das teorias antropológicas é muito baixo. Como mostrava o professor Roberto Cardoso de Oliveira, a antropologia é uma ciência poliparadigmática, onde as diversas escolas se refutam civicamente umas às outras sem que isso impeça a sua convivência. Se o que dá valor às teorias é sua suscetibilidade à refutação, deveria então se concluir que o caminho da antropologia não é por aí.

Desde Geertz se fez hábito reconhecer que, efetivamente, o caminho da antropologia não é por aí. Seu caminho pode ser, antes, o da interpretação e da tradução, mas o problema neste caso é quase o mesmo que no anterior: há tradutores demais. Há tempos que outros departamentos da academia se interessam por esses povos que antes os antropólogos monopolizavam. E os nativos não estão mais tão longe, falam fluentemente em inglês, português ou russo, muitos deles estudaram já filosofia, sociologia e antropologia. A autoridade do antropólogo-intérprete está em questão, na verdade deveria se fundamentar em algo externo à própria tradução, que já não se impõe por si mesma.

Enfim, e talvez por eliminação, a antropologia pode ser, no fundamental, uma ciência que descobre objetos. Pode ser que as teorias ou as interpretações de Boas, Malinowski, Evans-Pritchard ou Lévi-Strauss tenham perdido, como tais, algo do seu viço. Mas o potlatch, o kula, a organização segmentar, a aldeia circular bororo ou a lógica do sensível continuam a ser magníficos objetos, capazes de inspirar reflexões ou alternativas a isto ou aquilo. São fragmentos de outros pensamentos e outras práticas que a antropologia teve o mérito de introduzir numa tradição ocidental que, lá num pretendido topo, sofria de solipsismo e endogamia; não apenas conceitos, modelos não utópicos, reconhecidos em outras terras. Não por acaso, as tendências teóricas que mais interesse despertam no Brasil são aquelas que trazem dentro de si tais objetos: o que seria o "divíduo" melanésio de Strathern, senão um objeto dessa categoria? E por quê a actor-network theory, na sua versão Latour, estaria despertando tanto interesse, não fosse porque ela abre a opção de fazer de cada rede de atores um objeto 
novo, e não uma manifestação a mais do social? Se uma sociedade está viva deve ser porque produz objetos novos. Identificá-los e trazê-los para o debate público, alimentando esse debate antes que morra de uma espécie de anorexia, é algo que justificaria plenamente a existência da antropologia.

Mas a antropologia, um tanto surda à sua própria história, continua a se comportar como se fosse precisamente aquilo que já decidiu não ser: uma disciplina paradigmática. Estamos a criar cursos de antropologia em que, um ano após o outro, se ensina teoria antropológica. Os orientadores exigem e os estudantes aspiram a elaborar uma boa discussão teórica. Tudo isso é muito legítimo. Mas, curiosamente, não há a mesma pressão para que os pesquisadores descubram algum objeto novo: modesto, pequeno, mínimo se quisermos, mas novo. Há mesmo uma certa prevenção contra aspirações desse tipo: não seriam excessivas e desnecessárias? Afinal, o que se pode deduzir de uma discussão teórica onde em rigor não há refutação é que não há nada de novo sob o Sol? A praia toda está ocupada. E além disso, se a antropologia é uma ciência permanentemente jovem, então a exigência de originalidade de qualquer pesquisa talvez pudesse se cumprir descobrindo cada vez, por toda a parte, os mesmos novos objetos.

Mas será que podemos nos contentar com semear por toda a parte a boa nova de que a tradição é inventada ou a identidade de gênero construída? Creio que não: se a antropologia interessa é porque não há uma invenção ou uma construção idêntica a outra, e nosso esforço deve se concentrar precisamente aí, nessa diferença. A etnografia é o modo de optar pelo extremo mutante da realidade.

Devo precisar que eu, pessoalmente, estou convicto de que nada é assim tão novo sob o Sol. De fato, também não será assim tão nova a minha definição particular da antropologia como "uma ciência cujo objeto só está verdadeiramente definido no final da pesquisa", depois de ter fracassado na tentativa de aplicar um projeto elaborado nas aulas e na biblioteca. E, o que é mais importante, depois de ter assumido esse fracasso como uma prova de que nem tudo está escrito e que sair a campo ainda vale a pena. E falo em fracasso porque, em rigor, parece-me que não há objeto verdadeiramente novo se ele não se manifesta quebrando uma expectativa genuína do pesquisador, se ele não vai a campo convicto de que poderá abranger a realidade dentro do projeto que elaborou, conservando porém a arte suficiente para captar e valorar a violência que o mundo, mudando, exerce sobre o melhor juízo prévio possível. Não se trata, assim, de sair distribuindo certidões de novidade ou diferença, mas de estar atento ao que, por desígnio e força próprios, consiga de fato alterar as nossas propostas teóricas.

Assim, tendo a dar ao objeto um lugar que não está nem na realidade em si do positivismo nem no desígnio subjetivo do construtivismo. Quiçá um embate entre essas duas noções seja preferível. Para nós, esse objeto que está aí 
se tornou uma espécie de superstição positivista ou empirista. Mas o construtivismo, por sua vez, se converte com demasiada facilidade em academicismo, reduzindo a experiência à ilustração de alguma hipótese já consagrada nas obras em voga. Talvez o objeto em si, esse campo que tem a última palavra nas nossas pesquisas, seja uma superstição, mas uma superstição cuja força pode quebrar o monopólio das ideias estabelecidas. Talvez o vigor da etnologia indígena tenha a ver com isso. Em páginas anteriores sugeri que ela não está livre da tendência comum de replicar um esquema que já conta com dignidade acadêmica e eficácia social. Mas esse mesmo fetichismo do primitivo - ao qual a própria antropologia não é infensa, por muito que o exorcize - tem também a virtude de predispor o pesquisador a uma experiência que altere seus pressupostos.

Com as premissas anteriores, oferecer minha própria pesquisa de doutorado como exemplo de fracasso metódico (não como fracasso sem mais, afinal foi ela que me tornou doutor, foi publicada e indiretamente me garantiu um posto universitário) pode ser muito autocomplacente. Mas não poderia tomar a liberdade de aplicar esse rótulo a muitas outras pesquisas contemporâneas que, apesar de terem trazido novidades que contrariavam seriamente os seus pressupostos de pesquisa, preferem reformulá-los a posteriori para apresentar o trabalho como dotado de uma maior coerência de início. Estou aqui a insistir sobre uns bastidores da pesquisa que nem sempre precisam estar à mostra.

A minha pesquisa sobre os Yaminawa começou impulsionada por algumas ideias obsoletas sobre a sua primitividade putativa. Os Yaminawa eram um povo de contato relativamente recente, tinham se integrado muito precariamente na sociedade regional e por isso mesmo quase não tinham sido objeto de pesquisa. Eu não era, no entanto, ingênuo, não buscava um mundo perdido: de acordo com a literatura estudada, estava preparado para encontrar um universo híbrido onde os nativos acomodassem a experiência recente a suas demandas estruturais.

Mas de caminho ao meu campo fui ouvindo uma série de vozes agourentas: os Yaminawa eram um povo conflitivo, difícil de pesquisar, um povo sem cultura, que deixou de lado a sua cultura. Pior, um povo anômico. O grave dessas advertências era que em boa parte procediam - precisamente nesses termos - dos próprios porta-vozes dos Yaminawa com os quais negociei minha pesquisa.

Nenhuma dessas advertências era totalmente injustificada: os Yaminawa não cultivavam marcas de identidade, não celebravam rituais nem enunciavam teorias sobre a formação da pessoa nem outras exegeses sobre quaisquer outros temas. O que diziam sobre si mesmos e sobre as suas normas de aliança não permitia inferir um sistema de parentesco, ou, pior ainda, permitia inferi-los todos. Uma cisão conflitiva a cada cinco anos no máximo, constantes idas e voltas da aldeia à cidade e de uma aldeia a outra - com uma vida rala em cada 
uma delas - configuravam uma situação em que dificilmente um etnógrafo podia aprender uma língua, aperfeiçoar as suas artes e, em definitiva, realizar seu projeto.

O que poderia fazer com tudo isso? Desesperar, é claro, e me considerar um mau etnógrafo que não fora capaz de superar todos esses inconvenientes para atingir seu alvo. Esse juízo se manteve na minha consciência, mais ou menos ominoso, até que anos depois, numa breve visita a uma outra aldeia a dos Yawanawá do Rio Gregório, muito próximos linguística e culturalmente dos Yaminawa, mas envolvidos num projeto histórico totalmente diferente comprovei que exegeses sobre a construção do corpo, diagramas genealógicos, rituais e saberes xamânicos enchiam sem esforço as minhas cadernetas. Os Yawanawá eram os nativos perfeitos para um tipo de etnologia que eu tinha sido incapaz de realizar entre os Yaminawa. Talvez, simplesmente, eu tivesse escolhido os nativos errados? E pode haver algo como nativos errados?

Pude então reconsiderar com mais calma a minha velha e precária etnografia. Afinal, os mitos que tinha conseguido coletar em bom número (os Yaminawa eram, pelo menos, narradores muito bem dispostos) teriam me permitido uma reconstrução interessante da vida do passado. As raríssimas exegeses que me foram oferecidas, embora criações muito idiossincráticas deste ou daquele indivíduo que pouco eco tinham entre os seus pares, teriam também produzido excelentes efeitos nesse sentido. A própria existência "anômica" dos Yaminawa, relutantes a se integrar no panorama multicultural cultivando suas tradições, poderia se entender como fidelidade a um velho ethos guerreiro e anarquizante, como a continuidade de uma cultura sem aspas que impedia os Yaminawa de terem uma "cultura" com aspas, segundo a expressão de Carneiro da Cunha.

Mas o que fazer, então, com tudo o que, na falta de rituais e saberes tradicionais mais ou menos hibridados, constituía a minha experiência de fato com os Yaminawa? Considerar o que tinha presenciado como um epifenômeno daquilo que apenas podia inferir?

Não me arrependo, agora, de ter feito o contrário: de ter descrito e analisado como tais (e não como adaptação de rituais antigos) as festas feitas de forró e aguardente; nem de ter tomado como chefia yaminawa uma instituição incubada pelas ONG; nem de ter prestado atenção àquelas permanências na cidade que em princípio me pareciam tempos mortos para a minha pesquisa; nem de ter assumido como relato yaminawa uma história oral da qual a informação externa, tomada do diálogo com seringueiros ou com ativistas pró-índios, fazia parte essencial; nem de tomar nota de um tradicionalismo, presente neste ou naquele indivíduo, cuja sina estava precisamente em não conseguir se enraizar no grupo; nem de dar um lugar central a uma identidade ou um nome - "Yaminawa" - que evidentemente tinha caído sobre as cabeças dos meus nativos desde o céu das especulações dos brancos. Tudo isso estava, 
sem dúvida, relacionado com a estrutura, ou, se quisermos, com a antiestrutura tradicional dos Yaminawa, mas tinha vida própria.

A vida dos povos indígenas no Brasil está densamente ocupada por esses novos objetos que derivam, com certeza, de esquemas sociocosmológicos anteriores, como derivam também das próprias teorias e dos conceitos antropológicos que surgiram de etnografias anteriores, e que por muitos caminhos voltam para fazer parte da vida do nativo. Do mesmo modo, e para dar um exemplo muito fértil, as novas tecnologias de reprodução possibilitam na metrópole configurações de parentesco que são, de um lado, tributárias de padrões tradicionais, e, de outro, da reflexão crítica que se realizou a respeito destes, mas que, surgindo dessas fontes, andam já pelos próprios pés. Se a antropologia quer ser algo além de uma doutrina, não poderá se limitar a enquadrar essas novidades dentro de um quadro teórico que tende a dar voltas sobre si mesmo: terá que sair à caça de um objeto permanentemente selvagem.

The place and the time of the ethnographic object - Oscar Calavia Sáez - Programa de PósGraduação em Antropologia Social, Universidade Federal de Santa Catarina, Brasil • occs@uol. com.br. 